\title{
La ciudad capitalista en el patrón neoliberal de acumulación en América Latina
}

\author{
The capitalist city in the neoliberal pattern \\ of accumulation in Latin America
}

Emilio Pradilla Cobos

\begin{abstract}
Resumen
El desarrollo capitalista es desigual y combinado en el tiempo y territorio; por ello la ciudad latinoamericana tiene características particulares, específicas, que no pueden analizarse mediante conceptualizaciones que explicarían a las del mundo desarrollado. La histórica mundialización del capital - ¿globalización? - no homogeniza a las formaciones urbanas; las diferencia. Explicar la ciudad latinoamericana en el neoliberalismo vigente, implica analizarla en la generalidad capitalista y su particularidad latinoamericana, su combinación de lo nuevo y lo viejo, sus rasgos históricos específicos: subsistencia indígena; urbanización acelerada; industrialización tardía; desindustrialización temprana; terciarización informal; autoconstrucción masiva; mercado informal de suelo y vivienda; desempleo estructural, pobreza, informalidad; regímenes de excepción; baja ciudadanización; diversas posturas gubernamentales ante el neoliberalismo; violencia urbana generalizada; etc.

Palabras claves: capitalismo; desarrollo desigual; patrón neoliberal; ciudad latinoamericana; rasgos específicos.
\end{abstract}

\begin{abstract}
A combination of unequal capitalist development, time and territory produces Latin American cities with particular, specific characteristics that cannot be analyzed by concepts that are used to explain cities of the developed world. The historical capital globalization does not homogenize urban formations; rather, it differentiates them. Explaining the Latin American city in the current neoliberal pattern involves analyzing, in the capitalist generality and in its Latin American particularity, its combination of new and old, its specific historical features: indigenous subsistence; rapid urbanization; late industrialization; early deindustrialization; informal outsourcing; massive self-help housing; informal land and housing market; structural unemployment; poverty; informality; emergency regimes; low urbanization; various governmental positions concerning neoliberalism; widespread urban violence, etc.
\end{abstract}

Keywords: capitalism; uneven development; neoliberal pattern; Latin American city; specific features. 


\section{Introducción: el desarrollo desigual del capitalismo y las particularidades latinoamericanas}

Desde su formación o reconfiguración en el siglo XVI, las ciudades latinoamericanas estuvieron subsumidas, formal o realmente, al proceso de acumulación originaria de capital que engendró al capitalismo en las entrañas del feudalismo (Marx, [1867] 1976, cap. XXIV, t. 1, v. 3) en el que jugaron un papel sustantivo pero subordinado dadas las condiciones de dominación colonial a las que se encontraban sometidas (Pradilla, 2009, cap. I); desde entonces, siguieron las determinaciones y ocuparon los lugares estructurales que les impusieron los distintos y sucesivos patrones de acumulación de capital, ${ }_{1}^{1}$ en su relación dialéctica ${ }^{2}$ con las fases específicas de su inserción en la mundialización del capital (Pradilla, 2009, cap. VIII): expoliación colonial hasta las independencias, capitalismo mercantil en el siglo XIX e inicios del XX (patrón primario-exportador), intervencionismo estatal de 1940 a 1980 (industrialización sustitutiva de importaciones), y neoliberal después de 1982.

Por ello, desde entonces y a lo largo de su historia, las ciudades latinoamericanas han sido capitalistas $^{3}$ y en lo general, se explican a partir de la(s) teoría(s) ${ }^{4}$ y leyes generales que explican las formas sociales, la estructura, los procesos y las contradicciones del modo de producción capitalista. Sabemos también, desde Marx, que el desarrollo de las formas y relaciones sociales y de los modos de producción que conforman es desigual, y por tanto combinado, en el tiempo, la intensidad, la profundidad y el territorio (Pradilla, 2009, cap. I); esta lógica es reconocida ampliamente por Harvey en sus elaboraciones teóricas generales sobre el capitalismo, el territorio y la ciudad (Harvey, [1982] 1990, cap. XIII, 1 y 2; Harvey, [2000] 2003, pp. 93 y ss.).

Tanto la incisiva crítica teóricometodológica de Kalmanóvitz a los teóricos de la dependencia latinoamericana de los años setenta (Kalmanóvitz, 1977 y 1982, citado en Pradilla, 1984, pp. 622 y ss.), como la de Singer a Castells sobre su concepción de la urbanización dependiente y la marginalidad (Singer, 1973; Castells, 1973), nos mostraron hasta la saciedad que ni el desarrollo capitalista en América Latina ni la urbanización que genero han seguido el mismo camino histórico, ni iguales modelos, ${ }^{5}$ ni ocurrieron en los mismos tiempos y ritmos seguidos por estos procesos en Europa o Estados Unidos en los siglos XIX y XX, ni han dado lugar a ciudades y sistemas urbanos similares. Ningún tratado serio de historia general, económica, social o urbana de los siglos XIX y XX avala la posibilidad de la igualdad mundial del desarrollo.

Las razones fundamentales señaladas por Kalmanóvitz y Singer son: a) el papel diferenciado que asumen unas y otras sociedades en sus relaciones (colonizadores 0 dominantes, colonizados o dominados); b) las diferentes estructuras económicas, sociales, culturales y políticas que se conformaron en unas y otras sosedades, en su relación conflictiva con las sociedades pre-existentes, y las diferencias de sus condiciones de desarrollo; c) el papel activo de las clases sociales colonizadas o dominadas frente a las colonizadoras o dominantes, y sus conflictos, evidentes en la historia; d) las distintas 
temporalidades de los procesos en unas y otras sociedades; y e) las diferencias geográficas, medioambientales y territoriales pre-existentes o que se configuraron en estos procesos.

En la actualidad, el mito ideológico ${ }^{6}$ neoliberal de la globalización y su derivación en el de las ciudades globales (Pradilla, 2009, cap. VIII) han pretendido homogeneizar al planeta entero, y aplicar así en los países latinoamericanos, asiáticos o africanos, las mismas recetas de políticas económicas, sociales y territoriales engendradas en los países hegemónicos del patrón neoliberal de acumulación, imponer su verdad única, explicar sus procesos, incluidos los urbanos, mediante las mismas conceptualizaciones y modelos construidos para analizar los suyos propios, en una clara muestra de colonialismo intelectual, pasivamente aceptado por muchos en nuestra región (Pradilla, 2010b).

La imposición del patrón neoliberal de acumulación de capital, en sus tres décadas de historia, ha dado lugar a una creciente desigualdad del desarrollo capitalista entre los países hegemónicos imperialistas y los dominados y atrasados, y entre estos últimos, ${ }^{7}$ acentuando la fragmentación y diferenciación entre los países y sus formas territoriales; aún en las áreas dominadas del mundo, con condiciones histórico-sociales homólogas como América Latina, esta diferenciación se acentúa, por ejemplo entre Brasil o México y Haití u Honduras; así, el planeta aparece hoy como una combinación caleidoscópica, un mosaico de fragmentos profundamente desiguales en lo económico, lo social y lo urbano.

La naturaleza capitalista y la vigencia, también diferenciada, del patrón neoliberal de acumulación impuesto a la mayoría de las naciones del mundo por los organismos multinacionales (FMI, OMC, Banco Mundial) asignan generalidades y rasgos comunes a nuestras ciudades y las del mundo desarrollado, que son explicadas por las teorías generales; pero estos rasgos generales también se combinan con los heredados del pasado, de la propia historia particular de las formaciones sociales concretas, y los que surgen de sus desigualdades de desarrollo, que solo pueden ser explicados por el análisis concreto de las realidades concretas y diferenciadas. La presencia histórica en América Latina de formas y procesos socio-territoriales particulares, ausentes en Europa o los EUA, como la subsistencia de núcleos indígenas en el campo y la ciudad, las formas de propiedad colectiva de la tierra periurbana en México ${ }^{8}$ (1917 a 1992), la urbanización acelerada entre 1940 y 1980, la autoconstrucción masiva de vivienda popular generalizada en la región desde 1940, la formación y presencia actual de un mercado informal de suelo urbano, la llamada informalidad ${ }^{9}$ como actividad laboral de subsistencia ante el enorme desempleo estructural y la pobreza, la presencia recurrente de dictaduras militares y regímenes de excepción en la región sobre todo en los años setenta, la actual diversidad - discursiva 0 real - de las posturas gubernamentales ante el neoliberalismo, o la violencia generalizada en las ciudades en la actualidad debida en gran medida al narcotráfico y su incidencia en la vida cotidiana urbana, nos sirven a la vez para mostrar: que las teorizaciones y modelos urbanos globales homogeneizantes no tienen validez para nuestra región; y que existen rasgos generales propios de la región, gestados históricamente y agudizados 
en el neoliberalismo, que hacen viable la construcción de explicaciones latinoamericanas de esas particularidades comunes. Tenemos que entender también que aún en el contexto regional los procesos entre países, regiones y ciudades son desiguales, y que las conceptualizaciones regionales nos explican solo los rasgos generales y comunes entre ellos y no toda su especificidad.

\section{Las ciudades latinoamericanas en el patrón neoliberal de acumulación de capital}

En las últimas tres décadas, las ciudades latinoamericanas han sufrido grandes cambios demográficos, económicos, sociales, políticos, culturales y morfológicos cuya naturaleza y determinaciones debemos explicar y teorizar, tanto en su generalidad como producto de las relaciones capitalistas dominantes y del tránsito de un patrón de acumulación a otro, como en su particularidad histórica regional.

Estos cambios se han producido a partir de la aplicación - diferenciada en el tiempo, la intensidad y la profundidad en los distintos países - que no podemos suponer concluida ni irreversible, de las reformas estructurales que han materializado el cambio de patrón de acumulación de capital en la región, del intervencionista estatal al neoliberal, las cuales han modificado la arquitectura del capitalismo y su territorio, acentuando sus rasgos y contradicciones y generando nuevos conflictos socio-territoriales. Para avanzar en la caracterización y teorización de la ciudad capitalista que emergió durante el período de operación del patrón intervencionista estatal de acumulación de capital y el proceso simultáneo de industrialización sustitutiva de importaciones y urbanización acelerada, y de cómo se ha venido reestructurando con la implantación del patrón neoliberal de acumulación de capital, contamos con un acervo de investigaciones sobre las particularidades nacionales y urbanas, y los rasgos comunes a la región, que construyen sus conceptos e interpretaciones en el trabajo de análisis de las realidades concretas latinoamericanas mediante el uso de las teorías generales que explican la estructura, funcionamiento y contradicciones de la sociedad capitalista (ver Ramírez y Pradilla (comps.), 2013); en este esbozo, nos apoyaremos en una parte, limitada por el tiempo de elaboración y la dimensión de este trabajo, de este rico acervo latinoamericano.

\section{Las mutaciones del proceso de urbanización}

La fase más intensa de cambio de la distribución territorial de la población entre urbana y rural ocurrió en América Latina, desigualmente según los países, en el período 1940-1980, impulsado por la industrialización por sustitución de importaciones y su correlato, la penetración del capitalismo en el campo, la descomposición de las formas agrarias precapitalistas y la expulsión del campesinado hacia las ciudades, que dio lugar a altas tasas de crecimiento poblacional en ellas (Pradilla, 1981); hoy podemos afirmar que la región se acerca a la urbanización relativa casi total (Pradilla, 2009, caps. VI y VII). En las últimas 
décadas, han disminuido sustancialmente las tasas de crecimiento anual promedio de la población urbana, en especial en las metrópolis, lo cual no significa que se haya agotado totalmente el potencial de migración debido a que el crecimiento demográfico en el campo, a pesar de ser declinante, ha mantenido en él a una masa de población muy grande, que por lo general subsiste aún mediante formas pre-capitalistas o capitalistas atrasadas de producción.

La persistencia de la migración del campo y los pequeños poblados a las ciudades es motivada por la descomposición de las formas atrasadas de producción agraria aún subsistentes determinada por la pobreza, la carencia de servicios, la introducción de nuevas técnicas productivas, la exacerbación de la competencia desigual en el libre mercado con las formas productivas avanzadas internas o externas, la eliminación neoliberal de los subsidios públicos al campo y la continua expansión urbana sobre las tierras agrarias. La persistencia de la migración rural y entre ciudades, que se suma al crecimiento natural interno, o la integración de pueblos y pequeñas ciudades a las tramas urbanas, en las nuevas condiciones de la acumulación de capital, han acelerado los procesos de metropolización y formación de ciudades-región, ${ }^{10}$ que se han convertido en las formas urbanas características y dominantes del patrón de urbanización en el actual período histórico (Pradilla, 2009, pp. 263 y ss.).

Al interior de las metrópolis, asistimos también a intensos cambios de la distribución territorial de la población derivados de: la periferización de la vivienda de interés social construida por el capital inmobiliario en grandes mega-conjuntos o por los ocupantes irregulares y autoconstructores; el vaciamiento de población residente de las áreas centrales o los corredores terciarios donde la vivienda es sustituida por actividades terciarias y por grandes megaproyectos inmobiliarios mixtos destinados a las actividades empresariales y a vivienda de sectores de altos ingresos (Pradilla, 2010b). El resultado son tasas de crecimiento demográfico muy bajas o negativas en las áreas centrales, mientras en las periferias y en los asentamientos en proceso de integración a las metrópolis se alcanzan tasas muy superiores a la media urbana, lo cual mantiene un crecimiento físico más que proporcional al demográfico.

\section{Las rentas del suelo en los procesos de expansión y re-construcción urbana}

Los patrones de estructuración urbana en América Latina están determinados, en forma compleja, por las lógicas de formación de las rentas del suelo urbano tanto en los territorios periurbanos o intersticiales metropolitanos, como en las áreas ya integradas donde se articulan las viejas y nuevas condiciones estructurales de la acumulación de capital (Jaramillo, 2009). ${ }^{11}$

En las ciudades latinoamericanas funcionan hoy dos mercados de suelo urbano con reglas del juego distintas: el formal, plenamente capitalista y sometido a las regulaciones estatales de la propiedad y el urbanismo; y el informal que domina en las áreas carentes de titulación de la propiedad que fueron urbanizadas ilegal o irregularmente; el segundo, articulado y subsumido al primero, 
entra también en el juego de definición de las rentas del suelo urbano (Calderón, 2006; Eibenschutz y Benlliure, 2008; Abramo, 2011). Los gobiernos urbanos, desde los tiempos de la urbanización acelerada han tratado, por la represión o la regularización, de eliminar el mercado informal o de integrarlo al formal, sin que hayan tenido éxito pleno pues la pobreza y la ausencia de una oferta legal adecuada a los bajos niveles de ingreso, lo reproducen continuamente.

La coexistencia de estos dos mercados en las ciudades latinoamericanas es uno de sus rasgos específicos que las diferencian estructuralmente de las de los países hegemónicos e imponen la necesidad de una elaboración teórico-interpretativa propia.

Las rentas urbanas y su metamorfosis en precios del suelo inician en la intersección de lo urbano con lo rural, partiendo del nivel alcanzado allí por las rentas agrarias. En este límite, a los vectores históricos de la continua expansión urbana, en particular los procesos de ocupación irregular de terrenos para la autoconstrucción de vivienda popular, se combinan ahora como factores de la transformación del uso del suelo de rural a urbano y de formación e incremento de las rentas urbanas: los cambios en el régimen de propiedad de la tierra rural hacia su privatización (caso mexicano en 1992) y/o su concentración; la irrupción del capital inmobiliario-financiero en la producción de vivienda "de interés social" en las periferias lejanas para abaratar el costo del suelo, la cual transforma en urbanos y eleva las rentas en los terrenos que quedan libres entre sus proyectos inmobiliarios y el límite urbano anterior (Duhau, 2008; Eibenschutz y Goya, 2009, pp. 16 y ss.); las grandes infraestructuras viales producidas por el Estado o las empresas privadas, que impulsan el fraccionamiento y construcción del suelo aledaño; y la generalización de las ventajas de aglomeración en los ámbitos de las regiones urbanas que permiten la localización casi indiferenciada de actividades económicas en sus intersticios rurales (ver nota 10).

En el caso de la Zona Metropolitana del Valle de México, una de las dos mayores de la región junto con São Paulo, la expansión urbana ha ocurrido siguiendo un patrón de tipo cíclico, de expansión - consolidación expansión territorial (Duhau, 1998, pp. 131 y 281; Duhau y Giglia, 2008, p. 116) que, en su segundo movimiento implica la saturación de los terrenos intersticiales dejados libres en el movimiento expansivo, por nuevos asentamientos irregulares o empresariales. A pesar de las particularidades, entre las que destaca la diferencia de tendencias históricas hacia la verticalización y la compactación (Brasil o Argentina), o la expansión con baja densidad (México), creemos que esta característica se repite en diversas ciudades latinoamericanas (Ferreira, 2012, pp. 18 y 22; Pradilla, 2011). Este tipo de expansión difiere estructuralmente del que Dematteis caracteriza como disperso o difuso al referirse a las ciudades anglosajonas de Europa en el pasado, y su generalización actual en ese continente (Dematteis, 1998), o el patrón disperso de baja densidad históricamente dominante en las áreas de vivienda de las ciudades norteamericanas.

En el neoliberalismo, en las áreas ya integradas y centrales de las metrópolis, las diversas formas de la renta del suelo (Jaramillo, 2009, cap. IV), están dialécticamente 
articuladas con: los procesos de privatización de lo público urbano; los significativos cambios en la localización de las actividades urbanas (usos del suelo), determinados por los procesos de desindustrialización y terciarización metropolitana (Márquez y Pradilla, 2004 y 2008) y la formación de corredores terciarios (Pradilla y Pino, 2004; Pradilla, Moreno y Márquez, 2012a); y los nuevos procesos de verticalización emprendidos por el capital inmobiliario-financiero (Pradilla, 2010a), que modifican sustantivamente su funcionamiento, monto y distribución social, y son características determinantes y dominantes de la lógica actual de estructuración urbana.

El resultado es un crecimiento sostenido en términos reales de las rentas $y$, por tanto, de los precios del suelo urbano, de múltiple sentido territorial: de la periferia hacia el centro, del centro hacia la periferia, de la trama de corredores terciarios hacia el interior de las áreas de vivienda y otros usos, cuya orografía no puede explicarse desde esquemas concéntricos como los de la Escuela de Chicago; este crecimiento afecta sobre todo a los sectores más pobres de la sociedad, sean ellos compradores o locatarios de vivienda, eleva el costo de la vida en las metrópolis e incide en los procesos de empobrecimiento en ellas.

\section{La mercantilización y privatización de lo urbano}

Marx, al construir su teoría general sobre el modo de producción capitalista en El Capital ([1867] 1975) y muchos otros textos, señala claramente el papel de la mercancía y su realización en el ciclo del capital y su acumulación, la necesidad constante y creciente de los capitalistas de integrar a todo lo producido y aún lo no producido por el hombre (la tierra, el agua, el aire, los recursos naturales no renovables, etc.) al régimen mercantil, y el papel del fetichismo de la mercancía en el ámbito de la ideología como encubridor de las relaciones de explotación de los trabajadores por el capital (Marx, [1867] 1975, I. 1, t. 1, cap. II, 4). Se refiere también, premonitoriamente, a la tendencia a la privatización, mercantilización plena y capitalización de las condiciones generales del proceso social de producción - transporte, comunicaciones y almacenamiento en ese momento, pero que integran a muchos otros elementos considerados urbanos hoy en día (Pradilla, 1984, cap. II) - en la medida que el capitalismo se desarrolla (Marx, [18571858] 1972, v. 2, n. 22, citado en Pradilla, 2009, p. 125). En tiempos recientes, autores multicitados por los investigadores urbanos como Polanyi ([1957] 2003), Wallerstein ([1983] 1988, cap. 1), o Harvey ([1973] 1977, pp. 273 y ss.), se refieren ampliamente al proceso continuo, pero desigual, de mercantilización. Sobra señalar que las mercancías y el mercado en el que se intercambian, son las piedras claves de la construcción de la teoría económica burguesa, y en particular de su variante neoliberal.

En el patrón neoliberal de acumulación, esta mercantilización se ha acelerado, profundizado, y articulado intrincadamente con la privatización de lo público constituido o construido a partir de la intervención del Estado - incluyendo a su aparato legislativo ${ }^{12}$ - en etapas históricas anteriores, que constituye una de sus políticas fundamentales 
(Valenzuela, 1991, cap. II; Pradilla, 2009, cap. III). La privatización de lo público, que entrega al capital privado a las empresas productivas, comerciales, de servicios y las condiciones generales de la acumulación y de la reproducción social bajo su control, incluye a muchos ámbitos públicos urbanos: suelo e inmuebles públicos, plazas, parques, reservas naturales, vialidades, servicios sociales, áreas recreativas, etcétera, integrándolos a un amplio, profundo e incesante proceso de mercantilización de todos los elementos de la estructura urbana, incluidos los no producidos por el hombre.

Paradójicamente, esta privatización ha sido más acelerada, profunda y extensa en los países latinoamericanos que en los capitalistas hegemónicos, sobre todo los europeos, debido fundamentalmente a la poca capacidad defensiva real de los trabajadores y ciudadanos latinoamericanos ante las embestidas privatizadoras de sus gobernantes y empresarios neoliberales, que la de los ciudadanos europeos con gran tradición histórica de lucha defensiva de sus conquistas sociales y sus condiciones de vida. Estos hechos, constatables factualmente, muestran el carácter desigual de los dos procesos, que también se manifiesta entre los países latinoamericanos y sus ciudades, en el tiempo, la intensidad y la profundidad, lo que obliga a su diferenciación y particularización.

Estos dos procesos han sido claves para que el capital en su conjunto, en particular el inmobiliario-financiero y constructor, avance por múltiples caminos en su empoderamiento sobre la economía y el cambio urbanos.
La desindustrialización y la terciarización informal de las metrópolis

En las últimas décadas, los países latinoamericanos, en particular los de mayor peso económico relativo (Brasil, Argentina y México) han sufrido desigualmente lo que Pierre Salama denomina desindustrialización relativa prematura, debida a: la baja productividad del sector fabril; las altas tasas de interés en el mercado especulativo y abierto de capitales; la apreciación de sus monedas frente a las divisas internacionales; y la baja competitividad de sus precios de producción en el marco del proceso neoliberal de apertura comercial internacional (Salama, 2012a).

Este ha sido el contexto general nacional en el que ha ocurrido una desindustrialización relativa y/o absoluta de las metrópolis latinoamericanas industrializadas durante el período 1940-1980, cuya determinación multifactorial incluye, además de las razones generales, el crecimiento de las desventajas (deseconomías) de aglomeración derivadas de la saturación vehicular que alarga el tiempo y costo del transporte de materias primas, productos y trabajadores, la contaminación ambiental y el costo de las medidas para controlarla, la elevación de los precios del suelo y los impuestos prediales, los más elevados niveles salariales; así como de los efectos de las políticas públicas desindustrializadoras y la aceptación acrítica de la vocación terciaria de las metrópolis (Márquez y Pradilla, 2008).

La desindustrialización y las políticas públicas urbanas en ese sentido han 
determinado y/o acentuado la tendencia estructural hacia la terciarización de las economías metropolitanas propia de esta etapa del desarrollo capitalista. Sin embargo, en la región, la terciarización ha tenido un carácter espurio, polarizado y dominantemente informal notorio en la mayoría de los análisis empíricos, pues en 2002 la fuerza laboral en la informalidad alcanzaba en América Latina el 46,5\% (Tokman, 2007, p. 295) de la población económicamente activa total (PEA), superaba el $34 \%$ en algunas de las mayores metrópolis del continente y se concentraba fundamentalmente en el sector terciario (Portes y Roberts, 2005, pp. 40-41; Pradilla, 2010a). Esta característica dominantemente informal del sector terciario urbano latinoamericano es una diferencia sustantiva respecto de la señalada por diversos autores sobre la predominancia de los servicios especializados a la producción en las grandes metrópolis de los países hegemónicos en la economía mundial.

La conjunción de los dos procesos ha tenido consecuencias muy negativas para la vida económico-social metropolitana: pérdida del dinamismo económico por la desaparición del sector industrial, más dinámico que el terciario; caída de la productividad urbana media al dominar el sector terciario informalizado, de más baja productividad del capital y del trabajo que el industrial; déficit de la balanza comercial del territorio urbano específico dada la poca exportabilidad de los servicios; incremento del desempleo urbano; y caída del nivel de ingresos de los sectores populares al perderse los empleos fabriles mejor remunerados que los terciarios (Márquez y Pradilla, 2008).
Los impactos territoriales de ambos procesos combinados han sido: liberación de grandes terrenos industriales insertos en la estructura urbana, en muchos casos de alto precio, y cambio de su uso a terciario o habitacional para sectores de ingresos medios o altos; terciarización de los usos del suelo en áreas integradas a la trama urbana donde se desarrollan los corredores terciarios (ver item "Los cambios en el patrón de estructuración urbana") reemplazando antiguas áreas de vivienda y desplazando a sus habitantes; y multiplicación de las concentraciones lineales o zonales de comercio en la vía pública y otras actividades informales, en particular sobre los ejes viales, los corredores terciarios y áreas e inmuebles de gran flujo de peatones y usuarios como centros comerciales, servicios públicos, oficinas gubernamentales, lugares de recreación, etc.

\section{La hegemonía del capital financiero y su fusión con el capital inmobiliario}

Desde finales del siglo XIX, el capital financiero resultante de la fusión del capital bancario y el industrial y comercial, inició su carrera hacia la hegemonía como fracción del capital en el capitalismo; América Latina no fue la excepción, gracias sobre todo a la penetración del capital bancario extranjero y al crédito internacional solicitado por los sectores público y privado. Desde entonces, ha penetrado profundamente en el funcionamiento de la economía en su conjunto y en la vida cotidiana urbana a través del crédito a las personas y más recientemente a la proliferación de las tarjetas de crédito y débito (Pradilla, 2012). Su carácter 
abiertamente especulativo y parasitario ha estado presente en todas las crisis económicas sincrónicas a nivel mundial de las últimas tres décadas, sobre todo en la del 2008 (Rozo, 2010, cap. 1).

La fusión entre el capital financiero y el inmobiliario nacional y trasnacional, determinada por las características estructurales del sector de la construcción, ${ }^{13}$ se ha convertido en la fracción dominante en la inversión urbana, debido a la disminución rápida y la pérdida de protagonismo del capital productivo industrial, a que tiende a convertirse en el único sector productivo de valor en las metrópolis y al hecho de que crea gran cantidad de empleo, aunque sea de baja calificación laboral, de corta duración, estacional e inestable y mal remunerado. Por estas razones, los gobiernos urbanos, discursivamente de distinta ideología, tienden a otorgar privilegios e incentivar los negocios de esta fracción del capital en sus políticas urbanas, lo cual, como veremos en la sección "Las dinámicas de los movimientos sociales en las metrópolis", genera nuevas contradicciones urbanas y una modificación de los actores en los movimientos sociales urbanos. ${ }^{14}$

El capital inmobiliario-financiero expande, casi sin límites, a las ciudades al adquirir terrenos baratos y construir viviendas para distintos sectores sociales, incluido ahora el segmento de viviendas de interés social en mega-conjuntos de micro-viviendas en las periferias lejanas; al mismo tiempo, reconstruye las áreas centrales de las ciudades con sus productos emblemáticos: centros comerciales, torres de usos mixtos y conjuntos cerrados y segregados, etcétera, apoderándose de los incrementos de rentas del suelo generados colectivamente por el crecimiento metropolitano mismo (Pradilla, 2010a).

Las nuevas políticas neoliberales de vivienda popular tienden a ubicar el papel de las instituciones estatales de vivienda, en el lugar de bancos hipotecarios que financian a sus derechohabientes para que compren sus viviendas al capital inmobiliario, convirtiéndose así en sus promotores (Ferreira, 2012, pp. 39 y ss.; Puebla, 2002; Castro y otros, 2006).

La fracción inmobiliaria-financiera en la producción de vivienda fue el origen de la crisis, por sobreproducción, de 2008-2009 en Estados Unidos, para luego transmitirse a otros sectores económicos a través de los vínculos del capital financiero (Rozo, 2010, cap. 1); ha estado presente en las posteriores convulsiones de las economías europeas; y en México, el sector se enfrenta hoy a una seria crisis sectorial derivada de la ausencia de compradores para sus viviendas de interés social o su abandono y/o moratoria de pago, por su pésima calidad constructiva y muy mala localización en relación con las ciudades, la cual está relacionada con la desaceleración y bajo crecimiento reciente de la economía nacional.

\section{La pauperización de la fuerza de trabajo y la segregación socio-territorial}

La aguda desvalorización de la fuerza de trabajo asalariada se ha producido por la vía de la reducción del salario real - directo, ${ }^{15}$ indirecto $^{16}$ y diferido ${ }^{17}$ - y la eliminación o reducción de las prestaciones sociales en los contratos colectivos de trabajo, la flexibilización de la relación laboral - despido discrecional, 
fragmentación de la jornada laboral, reducción del escalafón de puestos de trabajo, exigencia de calificación múltiple de los trabajadores, contratos de corta duración, etcétera -, y la privatización de los servicios públicos con elevación de los precios. La eliminación de subsidios y la reducción del gasto público social, ha sido un eje básico de la política neoliberal en América Latina (Valenzuela, 1991, pp. 45 y ss.; Guillén, 1997, pp. 167 y ss.; Pradilla, 2009, cap. II). Estas políticas se han aplicado desigualmente en el tiempo, la intensidad en los distintos países. ${ }^{18}$

En el contexto de una reducción de la inversión para la formación bruta de capital fijo, un bajo crecimiento del Producto Interno Bruto desde 1982 y hasta ahora, y recesiones recurrentes (Cepal, 2004 y 2013, pp. 81-86; Pradilla, 2009, pp. 312 y ss.), los impactos sociales más inmediatos han sido: un reducido crecimiento del PIB per cápita (Cepal, 2013, p. 74), la elevación de la tasa de desempleo abierto, el crecimiento del sector informal, la caída del salario real sobre todo en las décadas iniciales de los ochenta y noventa cuando imperó la hiperinflación, la pérdida de participación del salario de los trabajadores frente a la ganancia empresarial en la distribución de la renta nacional, y una mínima reducción de los niveles de pobreza e indigencia urbanas a pesar de los gastos multimillonarios en programas focalizados en sectores muy vulnerables de corte fundamentalmente asistencialista (Cepal, 2013, p. 78; Tokman, 2007, pp. 294296). La mejoría relativa, desigual según los países, del salario real y la distribución del ingreso entre salarios y ganancias, registrada en la primera década del siglo XXI, partió de niveles muy bajos, y no ha permitido la recuperación de lo perdido en las dos décadas anteriores (Salama, 2012b, p. 648). La histórica desigualdad en la distribución del ingreso y su concentración en una minoría se han acentuado significativamente en este período (Cepal, 2013, p. 78); en este aspecto, deberíamos incluir también los efectos del incremento de los flujos de ganancias al extranjero derivados de la trasnacionalización del capital y la liberación de los flujos de mercancías y capitales (Cepal, 2013, p. 97), pues reducen la reinversión de ganancias y las rentas distribuidas al interior de los países.

La segregación socio-territorial en las ciudades latinoamericanas ${ }^{19}$ se fraguó en su fase de crecimiento acelerado - 1940 a 1980 -, teniendo como vectores articulados dialécticamente, a la desigualdad socioeconómica creciente, la formación de rentas y el mercado del suelo, las formas de producción de los soportes materiales urbanos, en particular la formación de viviendas del tipo vecindad o conventillo en las áreas centrales, la ocupación irregular de la tierra y la autoconstrucción de viviendas localizadas en los terrenos menos construibles y poco atractivos para los promotores inmobiliarios y los sectores de ingresos medios y altos, los fraccionamientos de capas medias y altas mediante la producción por encargo (Pradilla, 2012) y los valores ideológicos imperantes.

Durante las tres décadas de políticas neoliberales, el mantenimiento o incremento de la desigualdad y la polarización socioeconómica, y de la pobreza y la indigencia en los sectores populares urbanos es uno de los factores explicativos de la segregación territorial imperante en las 
ciudades latinoamericanas de hoy, pero en su articulación dialéctica con otros procesos: los cambios sustantivos en las rentas y los mercados - formal e informal - del suelo, las modificaciones ocurridas en la estructura de las formas productivas de lo urbano (Pradilla, 2012), las nuevas formas urbanoarquitectónicas impulsadas por el capital inmobiliario-financiero (megaproyectos de renovación urbana, centros comerciales, corredores terciarios, clubes privados, edificios mixtos, conjuntos cerrados, macro-conjuntos de vivienda de interés social, etc.), y los gobiernos locales: revitalización y renovación urbana, revalorización de centros históricos, construcción de vialidades confinadas y otras obras viales (Sabatini, 2003, p. 6). Hay también que añadir el predominio del automóvil individual en los desplazamientos urbanos, la individualización de la vida cotidiana en la ideología, y la formación de territorios de la violencia creciente. ${ }^{20}$

La fragmentación socio-territorial de las ciudades, que implica a la vez la desigualdad social, la segregación territorial y la existencia de barreras físicas o socio-culturales como la violencia, a la movilidad, se ha incrementado a partir de la multiplicación de los conjuntos cerrados y cercados para clases medias y altas, el aislamiento territorial de los mega-conjuntos de interés social, la proliferación de vialidades confinadas y segundos pisos viales como barreras físicas, y las creadas por los guetos de la violencia urbana (Carrión, 2006).
La movilidad urbana y el dominio del automóvil

La movilidad y la conectividad se han convertido en temas predilectos del discurso de los gobiernos urbanos y de la investigación, precisamente cuando los recorridos urbanos han alcanzado una gran extensión y complejidad, la saturación de las vialidades y los medios de transporte público llegan a niveles críticos y se alarga significativamente el tiempo dedicado a los desplazamientos. Los factores estructurales hay que encontrarlos en el crecimiento poblacional y la continua expansión territorial de las ciudades, la complejidad alcanzada por las actividades urbanas, la generación de múltiples polos de atracción de los desplazamientos debido al surgimiento disperso de las nuevas formas urbano-arquitectónicas, el papel protagónico de la industria automotriz en las economías regionales y sus prácticas publicitarias y de crédito, el rezago y mala calidad del transporte colectivo público o privado, y la creciente individualización de la vida cotidiana acrecentada por la violencia urbana.

El transporte urbano de pasajeros es realizado cada vez más en automóvil, ${ }^{21}$ mientras se acentúa el deterioro e insuficiencia del transporte colectivo público o concesionado a actores privados, donde aún dominan en muchos casos los medios de transporte más irracionales o contaminantes como los microbuses o pequeños autobuses 
organizados precariamente en cooperativas 0 asociaciones atrasadas. A pesar del desarrollo reciente de sistemas como los metro-buses ${ }^{22}$ confinados y los trenes subterráneos o de cercanía en algunas ciudades, públicos 0 privados, de alto precio, el automóvil es privilegiado por las políticas públicas mediante la continua construcción de vialidades confinadas o en segundo piso, distribuidores viales, puentes y subterráneos, en muchos casos realizados y/o administrados por el capital privado nacional/extranjero, de cuota y excluyentes, a partir de visiones pragmáticas y realistas impregnadas por la ideología neoliberal de la privatización de lo público. Estas obras y sus efectos multiplicadores sobre el uso del auto, impactan negativamente sobre el funcionamiento del trasporte público, se convierten en barreras de fragmentación socio-territorial, y afectan la vida cotidiana del sector mayoritario de la población.

Los peatones, en particular los niños, mujeres embarazadas, discapacitados y ancianos, son los grandes olvidados por las políticas de movilidad, transporte y vialidad: cada vez más tienen que enfrentar barreras infranqueables como las vías rápidas y/o confinadas, los segundos pisos y distribuidores viales, los subterráneos y puentes o los elevados y distantes puentes peatonales; el automóvil, el artefacto más icónico del capitalismo industrial del siglo XX (¿y XXI?) es el dueño absoluto de la calle y la ciudad (Márquez y Pradilla, 2007).

\section{Los cambios en el patrón de estructuración urbana}

En las grandes metrópolis y ciudades medias en expansión, emerge una lógica diferente de estructuración urbana basada en una trama de corredores terciarios lineales, sobre grandes ejes de vialidad y de flujos de personas y mercancías, de diversa intensidad de actividad, de densidad inmobiliaria y de área de influencia, que sustituyen a las centralidades ampliadas del período de la industrialización y al poli centrismo de transición ${ }^{23}$ (Pradilla y Pino, [2002] 2004; Pradilla, Moreno y Márquez, 2012a; Pradilla (coord.) y otros, 2012, cap. VI).

Las determinaciones de este cambio estructural tenemos que encontrarlas en una combinación compleja de factores, entre ellos: el crecimiento poblacional y físico de las ciudades que dispersa a la población en grandes extensiones territoriales; las necesidades de abasto comercial y de servicios en áreas cada vez más alejadas de la antigua centralidad; la respuesta privada y pública a este mercado de bienes y servicios territorialmente localizado; la libre circulación internacional de mercancías y capitales; la multiplicación de formas terciarias como centros comerciales, tiendas en cadena y franquicias; las nuevas formas urbanoarquitectónicas desarrolladas por el capital inmobiliario-financiero nacional y trasnacional que se ubican privilegiadamente en estos corredores de flujos para apropiarse de las ventajas de aglomeración que allí se forman y/o 
contribuyen a formar; el dominio del automóvil privado como medio de transporte urbano; y las políticas promocionales públicas que los consideran ámbitos de desarrollo económico y urbano en la terciarización asumida como vocación de las ciudades. Paradójicamente, los corredores terciarios también se convierten en lugares de concentración del comercio informal en la vía pública cuando este es tolerado por los gobiernos locales, complementando al sector formal en el abasto de los compradores pobres y los empleados formales de bajos ingresos que no pueden acceder a lo vendido por sus empleadores (Duhau y Giglia, 2008).

\section{La desigualdad social en la apropiación de las nuevas tecnologías}

La introducción de los nuevos productos y procesos resultantes de la aplicación del conocimiento científico y tecnológico, ha sido muy desigual en los diversos sectores de la actividad urbana: por ejemplo, es muy importante en los campos de la comunicación y trasmisión de la información ${ }^{24}$ o la salud, menor pero notoria en el transporte, y muy poco significativa en el suministro de agua potable o la eliminación de desechos líquidos y sólidos.

La apropiación social de estas nuevas tecnologías es muy desigual, tanto en su acceso como en su uso en los procesos productivos, de acumulación de capital o de reproducción social, de acuerdo a la ubicación de los sujetos en la estructura de clases y de distribución del ingreso. Excluyen a sectores productivos, comerciales o de servicios como las micro y pequeñas empresas, y en su adquisición y uso a sectores mayoritarios de trabajadores urbanos y acentúan la segregación socio-territorial.

Estas dos desigualdades implican que su papel en la modificación de aspectos diversos del funcionamiento estructural y de la vida cotidiana urbana sea muy diferenciado y desigual, lo que nos lleva a dejar de lado las caracterizaciones generales, a veces propias de un futurismo sin sustento, y analizar en lo concreto, en nuestra realidad, sus desigualdades y sus efectos específicos y particulares.

\section{La extinción de la planeación y la subordinación de las políticas urbanas al capital}

En el patrón de acumulación con intervención estatal, la planeación urbana indicativa gozaba de legitimidad y contaba con los instrumentos, limitados, que se derivaban del papel que tenía el Estado en la arquitectura de la actividad económica, social y política. Sin embargo, su práctica real en el ordenamiento racional de la construcción y re-construcción de lo urbano fue limitada, insuficiente y con frecuencia inadecuada para enfrentar el crecimiento urbano acelerado resultante de la acción individualizada, espontánea de los múltiples actores urbanos.

Esa planeación no fue sistemática y continua en el tiempo; no se aplicó en todos los centros urbanos que la requerían; con frecuencia fue realizada por agentes privados (consultores o despachos de urbanismo) sin conocimiento de las lógicas políticas y sin capacidad de decisión; se pensó como plan documento estático y no como proceso 
permanente y dinámico; careció de una base científica de análisis de la problemática a resolver; cuando existió, se modificó cada vez que cambiaba el gobierno por lo que careció de continuidad; se subordinó a los intereses de los sectores sociales hegemónicos y del capital inmobiliario; no incluyo la participación ciudadana como elemento de validación y aceptación social; careció de los instrumentos de acción suficientes y adecuados a la problemática a enfrentar y a su aplicación, particularmente ante las acciones irregulares de los promotores inmobiliarios para las clases medias y altas y los ocupantes y autoconstructores del sector popular (Pradilla, 2009, pp. 201 y ss.).

En el patrón neoliberal de acumulación, desapareció esta legitimidad ante la ideología y la política dominaste: la desregulación de la vida económica y social, el adelgazamiento del Estado, su cambio de función de interventor a facilitador de la acción privada, la libre iniciativa y el libre mercado como formas de funcionamiento de la economía en el territorio, el fortalecimiento del capital inmobiliario-financiero nacional y extranjero en el marco del libre flujo internacional de capitales, y el nuevo protagonismo del capital privado (Pradilla, 2009, pp. 205 y ss.). Aunque se mantenga la elaboración de planes de desarrollo urbano por cuestiones legales ${ }^{25} 0$ de legitimación discursiva e ideológica, su eficacia y operatividad se desvanece en el aire ante las nuevas condiciones de operación del Estado capitalista en el neoliberalismo.

De hecho, tanto en el intervencionismo estatal como en el neoliberalismo, lo que ha operado y opera son las políticas urbanas entendidas como:
Todas aquellas acciones, prácticas 0 discursivas, que llevan a cabo los distintos poderes del Estado (Ejecutivo, Legislativo, Judicial, militar) en diferentes campos de la actividad económica, social, política, territorial, cultural, etcétera, que tienen efectos directos o indirectos, temporales o duraderos, sobre las estructuras y el funcionamiento de las ciudades. (Pradilla, 2009, p. 198)

Las políticas urbanas de los gobiernos locales, poco diferenciadas en términos de la ideología declarada de los partidos gobernantes, se han hecho pragmáticas y en ocasiones banales, ${ }^{26}$ responden a los imperativos neoliberales, ideológicos 0 reales, del libre mercado, la globalización, la competitividad entre ciudades, la rentabilidad del territorio, la vocación terciaria, la conectividad, la movilidad, la gobernanza, etc. En realidad, se someten a las razones o dictados del capital y sus cabilderos: a la privatización y la mercantilización creciente de lo urbano, a la rentabilidad de los negocios urbanos, al capital inmobiliario-financiero como fracción dominante en la producción de lo urbano y sus intervenciones, a los intereses de las trasnacionales automotrices, etcétera, aunque tengan que afectar más a los sectores mayoritarios 0 , aún, a sectores medios y altos en sus barrios y colonias.

\section{Las dinámicas de los movimientos sociales en las metrópolis}

A pesar de la agudización de las contradicciones sociales urbanas, los movimientos urbanos populares se han debilitado relativamente, muy desigualmente en el tiempo y el territorio según 
los países y ciudades, en lo que se refiere a sus reivindicaciones históricas de tierra, vivienda y servicios, bajo los impactos del cambio de función del Estado, el clientelismo político sobre todo de los partidos locales "de izquierda", las nuevas políticas asistencialistas de vivienda, 0 la presencia y prácticas desmovilizadoras de muchas ONGs; sin embargo, aparecen también nuevas causas urbanas para su movilización como la reivindicación del derecho a la ciudad, o la defensa ante los mega-eventos y sus impactos sobre la vivienda popular en Brasil en los años 2012 y 2013.

La novedad actual es que la articulación estrecha entre gobiernos locales y capital inmobiliario-financiero, en los megaproyectos urbanos públicos y privados (grandes conjuntos de usos múltiples y/o cerrados, vialidades confinadas y elevadas, inmuebles y complejos para los mega-eventos, etc.), o en las intervenciones privadas de re-producción, renovación y verticalización urbana, afecta crecientemente a sectores medios y altos en sus lugares de vivienda y ha llevado a la integración de estos sectores, puntual y fragmentádamente, a movimientos de oposición, a la vez, al capital inmobiliario y a los gobiernos locales (para la ZMVM, ver Pradilla, Moreno y Márquez, 2012b).

En el período, se han operado dos desplazamientos significativos en la reivindicación y la confrontación social por razones urbanas o urbanizadas. En primer lugar, la aparición de múltiples movimientos interclasistas y/o sectoriales por reivindicaciones y problemas nuevos como la igualdad de género, la diversidad sexual, la exclusión social, la ecología, la discapacidad, la violencia urbana, etc. En segundo lugar, el desplazamiento del discurso político, la investigación y las prácticas sociales, de los movimientos como procesos colectivos, hacia la participación ciudadana, individualizada, controlada y restringida por el Estado y sus regulaciones, sin que este le otorgue un papel decisorio en la gestión urbana, dominada por burocracias políticas neoliberalizantes; este desplazamiento busca debilitar a los movimientos sociales clasistas, al tiempo que evadir la toma de conciencia de una participación que trasforme a la sociedad y la ciudad. ${ }^{27}$

\section{La violencia y la vida cotidiana en la ciudad}

En las tres décadas transcurridas desde la gran crisis económica de 1982, las ciudades latinoamericanas se han hecho cada vez más violentas, dando lugar a un imaginario social del miedo, sobre todo urbano, al reconocimiento social de "espacios" del miedo ${ }^{28}$ y a modificaciones sustantivas de las prácticas sociales cotidianas urbanas en función de uno y otros: rutas de desplazamiento, lugares de recreación, cierre de calles en áreas de vivienda, multiplicación de inmuebles y unidades de vivienda cerradas y amuralladas, controles de policías privadas, uso de centros comerciales en lugar de la calle y las plazas públicas, etc. (Carrión, 2006).

Aunque no podemos caer en el simplismo lineal de asignar al neoliberalismo como patrón de acumulación la causalidad del fenómeno de la agudización de la violencia, si podemos constatar que ella ha ocurrido en este periodo. 
Se habla de la globalización de la delincuencia organizada en el narcotráfico, el contrabando de armas y muchos otros productos, el tráfico internacional de seres humanos, el secuestro de personas, etc., actividades por naturaleza violentas como lo ejemplifican los casos de Colombia en la década del ochenta o México en la actualidad. Su alta rentabilidad y la masa de dinero que mueven las organizaciones criminales, articuladas trasnacionalmente, les permiten penetrar las estructuras políticas y estatales, usar la corrupción y mediante ella gozar de amplios márgenes de impunidad. El incremento del desempleo, la multiplicación de la informalidad, y la exacerbación de la pobreza, en este período, nos permiten explicar por qué, donde y como encuentran las mafias a sus ejércitos de sicarios, como carne de cañón sacrificable. Estas realidades nos explican también la multiplicación de la delincuencia incidental, espontánea, que se registra en las calles de nuestras ciudades.

\section{A manera de conclusión: lo nuevo y lo viejo, lo común y lo diferente en la lógica de estructuración urbana}

Los países y ciudades de América Latina, se estructuran y funcionan hoy, en términos generales, siguiendo las determinaciones del patrón neoliberal de acumulación de capital, que tiene ya una edad de más de treinta años, el cual ha determinado una nueva fase de su historia. En ella, lo viejo, lo heredado del pasado, se ha combinado y mutado con lo nuevo, en una estructura compleja que suma y potencia los problemas y contradicciones del pasado y el presente, así como las prácticas y políticas de los distintos actores según sus intereses, divergentes u opuestos. Aunque el patrón neoliberal de acumulación ya ha mostrado sus deformaciones estructurales, ${ }^{29}$ no es aún posible predecir su sustitución por otro, pues aún es sostenido por los países hegemónicos y los empresarios trasnacionales, grandes beneficiarios de su carácter especulativo y expoliador.

Lo que se mantiene es el imperativo y las determinaciones de las relaciones técnicas y sociales del modo de producción capitalista, el dominio y la explotación del trabajo asalariado y otras clases dominadas, por el capital, como la base de la acumulación de riqueza; y por lo tanto, el carácter capitalista como lo general de las formas urbanas en los sucesivos patrones de estructuración.

Las ciudades capitalistas latinoamericanas que también han asumido diferentes estructuras y morfologías a lo largo de su historia, adquieren ahora las características, los rasgos generales del neoliberalismo. Sin embargo, a pesar de que comparten estos rasgos, no podemos confundirlas con las ciudades de las sociedades de los países hegemónicos en el mundo capitalista, porque ellos son formaciones sociales concretas diferentes, con historias distintas, y porque ocupan una posición distinta, dominante, en la cadena de depredación del mundo capitalista; debemos, tenemos que explicarlas en su particularidad social e histórica, sin caer en el recurso fácil de utilizar las interpretaciones, validas o no, que explicarían a las ciudades del capitalismo avanzado, y menos aún las 
mitologías neoliberales de moda, espuriamente generalizadoras.

A lo largo de este texto, que se sustenta en la investigación original desarrollada por muchos investigadores urbanos latinoamericanos, citados algunos, muchos otros no debido a la dictadura del tiempo y la extensión, hemos tratado solamente de articular entre sí algunas de las formas y procesos económicos, sociales, ideológicos y territoriales, presentes en las realidades urbanas latinoamericanas, resaltando tanto sus rasgos comunes como sus particularidades y sus diferencias con las formas y procesos urbanos que se han desarrollado en los países dominantes del capitalismo y, en algunos casos, sus propias diferencias.

Los rasgos comunes a las diferentes ciudades latinoamericanas nos permiten construir una interpretación y teorización macro-regional, mientras que las diferencias nos remiten a las particularidades nacionales 0 , aún, micro-regionales a su interior, resultantes de las particularidades que diferencian a una formación social de otras, y sus desiguales grados y procesos de desarrollo.

Avanzar en una teorización válida para las ciudades de América Latina, ha sido en el pasado y lo seguirá siendo, un trabajo colectivo, a veces anónimo, acumulativo y necesariamente crítico, que no podemos desechar por motivos de actualidad, precisamente porque lo viejo y lo nuevo se combinan en la realidad y, también, en su explicación. Es de lamentar y hay que criticar que este esfuerzo latinoamericano sea ignorado con demasiada frecuencia por los investigadores de países desarrollados cuando generalizan sus propias explicaciones al mundo entero, por muchos de nuestros propios investigadores, y por las grandes editoriales de lengua castellana o portuguesa también dominadas por el capital trasnacional.

\section{Emilio Pradilla Cobos}

Universidad Autónoma Metropolitana - Unidad Xochimilco, División de Ciencias y Artes para el Diseño, Departamento de Teoría y Análisis. México DF, México.

epradillacrm@hotmail.com 


\section{Notas}

(1) Entendemos por patrón de acumulación de capital, a la "arquitectura" que asumen los diferentes componentes estructurales de una formación social concreta en un período determinado y sus reglas de operación, para garantizar la reproducción simple o ampliada del capital. Estos patrones han cambiado, local y/o internacionalmente, en diferentes momentos de la historia del capitalismo, su desarrollo es desigual en diferentes formaciones sociales, y sus resultados y contradicciones también lo son.

(2) Como veremos más adelante, las formaciones sociales latinoamericanas no han sido, ni son, pasivas en esta relación; sus estructuras y actores sociales han actuado de una forma u otra en ella.

(3) En los distintos grados de desarrollo determinados por la ubicación de la nación, la región y la ciudad en el patrón de acumulación vigente en ese momento.

(4) En aras del debate teórico, podríamos incluir a las teorías burguesas que, desde el punto de vista del capital y los capitalistas, explican su lógica y la de la explotación de la fuerza de trabajo, desde las clásicas hasta las neoliberales.

(5) Agregaríamos, en general, que la "modelización" de los procesos socio-territoriales es un artificio metodológico espurio, acientífico, para igualar, generalizar y eternizar estructuras y procesos que solo se constatan en casos particulares, históricamente datados.

(6) Todo mito ideológico se asienta sobre algunos hechos de la realidad que se sistematizan, se generalizan, se magnifican y se convierten en verdad única e incontestable que no hay que comprobar por que forma parte de la ideología social dominante, aceptada por todos independientemente de su lugar en la estructura económica, social o política, formando parte de la falsa conciencia.

(7) Las llamadas economías emergentes, las del grupo BRIC, ejemplifican esta diferenciación del desarrollo capitalista entre los países dominados o atrasados.

(8) La propiedad ejidal y la comunal de la tierra rural, restauradas en la Constitución de 1917, intransferibles e inalienables, se mantuvieron así hasta 1992 y tuvieron un papel fundamental en la forma que asumió el crecimiento urbano en el período 1940-1980.

(9) Aunque consideramos este concepto inconsistente teóricamente, no conocemos otro alternativo, ni lo hemos construido, por lo que lo usamos a regañadientes.

(10) "Entendemos la ciudad-región como un gran sistema urbano uni o multi-céntrico, como una trama densa pero no necesariamente continua, de soportes materiales de infraestructuras y servicios, viviendas, actividades económicas, políticas, culturales, administrativas y de gestión, resultante de la expansión centrífuga de una o varias ciudades o metrópolis cercanas, que articula y/o absorbe a otros asentamientos humanos en su periferia o a lo largo de las vialidades y transportes que los unen y a las áreas rurales intersticiales; este conjunto está integrado como un todo único pero contradictorio, por una alta intensidad de relaciones y flujos permanentes de mercancías, personas, capitales, mensajes e informaciones; en esta trama, la localización de actividades es relativamente indiferente en la medida que sus lugares comparten los efectos útiles de aglomeración y las ventajas comparativas" (Pradilla, [1998] 2009, p. 263)

(11) El libro de Samuel Jaramillo desarrolla en forma sistemática, rigurosa y precisa el funcionamiento de las rentas del suelo agrario, su transformación en rentas urbanas y las formas que asumen estas en la ciudad capitalista de hoy, y en particular en la ciudad latinoamericana. 
(12) Por ejemplo, en la legislación que define al subsuelo, a las corrientes de agua, o a determinadas tierras como propiedad de la nación.

(13) La larga duración del proceso constructivo de los inmuebles derivada de su ubicación en un sitio determinado, como proceso de ensamblaje y el bajo desarrollo de las fuerzas productivas en el sector; y el largo período de recuperación del precio de producción del inmueble por su alto costo, lo que implica la presencia de un agente financiero diferente al promotor inmobiliario: la banca hipotecaria (Pradilla, 2012).

(14) Ver el conjunto de trabajos sobre São Paulo, Buenos Aires, Ciudad de México, Santiago de Chile y otras ciudades latinoamericanas incluido en la compilación de Pereira (2011).

(15) Entregado periódicamente en dinero al trabajador por el empleador.

(16) Recibido por el trabajador mediante los servicios públicos estatales subsidiados: agua, energía, transporte, educación, salud, etc.

(17) Recibido como prestación social o derecho cuando las condiciones del trabajador lo exigen o permiten, como vivienda, salud, servicios funerarios, etc.

(18) La intensidad en su aplicación fue mucho mayor en las décadas de los 80 y 90, cuando se aplicaron simultánea e intensivamente en todos los países, con frecuencia por gobiernos dictatoriales; disminuyó su intensidad en la primera década del siglo XXI en algunos países gracias en parte a la presencia de gobiernos democráticos y/o de izquierda, discursivamente anti neoliberales.

(19) Sobre este tema, en lo teórico y factual, ver el trabajo de Francisco Sabatini (2003).

(20) Para el caso de la ZMVM, ver: Rubalcava y Schteingart (2012) y Pradilla (coord.) (2013).

(21) Una mayoría de automóviles privados subutilizados satura las vialidades y el tránsito, circulando o estacionados, pero transporta a una minoría de los viajeros urbanos.

(22) En cada ciudad, iniciando en Curitiba, Brasil, se le ha dado una denominación distinta a este sistema.

(23) Hemos llevado a cabo trabajos empíricos sobre la Zona Metropolitana del Valle de México y observaciones sobre otras ciudades mexicanas que confirman nuestra hipótesis; también los recorridos realizados en algunas metrópolis latinoamericanas nos sugieren que ocurre algo similar en estadios diferentes de desarrollo, para las que habría que llevar a cabo estudios empíricos para confirmarlo.

(24) No compartimos las versiones teórico-analíticas que asignan al cambio tecnológico en la informática un papel central en la organización social en su conjunto y en la ciudad (modo de producción informacional, sociedad de la información, ciudad imformacional, cibercity, etc.) por considerarlas teóricamente insustentables, no coincidentes con lo real, y preñadas de determinismo tecnológico.

(25) En México, por ejemplo, se mantiene vigente la Ley de Planeación Democrática aprobada en 1983, cuando se iniciaban las reformas neoliberales que la harían ineficaz, la cual contiene la obligación de cada nuevo gobierno Federal, Estatal o Municipal de elaborar Programas Generales de Desarrollo y de Desarrollo Urbano.

(26) Poco significativas en relación con los problemas socio-territoriales a enfrentar, o simplemente resultantes de las modas o mitos del la modernización neoliberal.

(27) Sobre estos temas, es muy significativo y útil el trabajo crítico de Sergio Tamayo (2010). 
(28) Ciudades enteras consideradas violentas, incluidas en rankings mundiales, como Ciudad Juárez o Monterrey en México, o ámbitos territoriales como los Centros Históricos en general, las favelas en las ciudades brasileñas, Tepito o partes de la Delegación Iztapalapa en la ciudad de México, el bronx bogotano, por ejemplo.

(29) La generalizada y profunda recesión económica de 2008-2009, aún no superada, es una muestra de estas deformaciones estructurales y, también, de cómo se cargaron sus costos a todos los ciudadanos a través de los "rescates" gubernamentales de grandes bancos, fondos de inversión, monopolios industriales trasnacionales, y empresarios de naciones enteras, como Grecia y otros (Rozo, 2010).

\section{Referencias}

ABRAMO, P. (2011). "O mercado de solo informal em favelas e a mobilidade residencial dos pobres nas grandes ciudades brasileiras: notas para delimitar um objeto de estudo". In: NATAL, J. (org.). Território e planejamento. Rio de Janeiro/IPPUR, URFR, UFRJ/Letra Capital.

CALDERON COCKBURN, J. (2006). Mercado de tierras urbanas, propiedad y pobreza. Lima, Peru, Lincoln Institute of Land Policy, Sinco Editores.

CARRIÓN MENA, F. (2006). La inseguridad en la ciudad: hacia una comprensión de la producción social del miedo. EURE, n. 97. Santiago, Chile.

CASTELLS, M. (1973). "La urbanización dependiente en América Latina”. In: CASTELLS, M. (comp.). Imperialismo y urbanización en América Latina. Barcelona, Espanha, Gustavo Gilli.

CASTRO, J.; COULOMB, R.; LEÓN, P. e PUEBLA, C. (2006). “Los desarrolladores y la vivienda de interés social”. In: COULOMB, R. e SCHTEINGART, M. (coords.). Entre el Estado y el mercado. La vivienda en el México de hoy. México, Universidad Autónoma Metropolitana, Azcapotzalco y Miguel Ángel Porrúa.

COMISIÓN ECONÓMICA PARA AMÉRICA LATINA Y EL CARIBE (CEPAL) (2004). Una década de desarrollo social en América Latina 1990-1999. Santiago de Chile, Organización de las Naciones Unidas.

(2013). Estudio económico de América Latina y el Caribe 2013. Santiago de Chile, Organización de las Naciones Unidas.

DEMATTEIS, G. (1998). "Suburbanización y peri urbanización. Ciudades anglosajonas y ciudades latinas". In: MONCLUS, F. J. (ed.). La ciudad dispersa. Suburbanización y nuevas periferias. Espanha, Centre de Cultura Contemporánea de Barcelona.

DUHAU, E. (1998). Habitat popular y política urbana. México DF/México, Miguel Ángel Porrúa y Universidad Autónoma Metropolitana-Azcapotzalco.

(2008). Los nuevos productores del espacio habitable. Ciudades, n. 79. México DF/México, Red Nacional de Investigación Urbana.

DUHAU, E. e GIGLIA, A. (2008). Las reglas del (des)orden: habitar la metrópoli. México DF/México, Siglo XXI y Universidad Autónoma Metropolitana-Azcapotzalco. 
EIBENSCHUTZ HARTMAN, R. e ESCOBEDO, C. G. (coords.) (2009). Estudio de la integración urbana y social en la expansión reciente de las ciudades en México, 1996-2006: dimensión, características y soluciones. México DF/México, Cámara de Diputados/Sedesol/UAM-Xochimilco/Miguel Ángel Porrúa.

EIBENSCHUTZ HARTMAN, R. e BENLLIURE B. P. (coords.) (2009). Mercado formal e informal de suelo. Análisis de ocho ciudades. México DF/México, UAM-Xochimilco/Miguel Ángel Porrúa.

FERREIRA, J. S. W. (coord.) (2012). Produzir casas ou construir cidades? Desafios para um novo Brasil urbano. São Paulo, Faculdade de Arquitetura e Urbanismo, Universidade de São Paulo.

GUILLÉN ROMO, H. (1997). La contrarrevolución neoliberal. México, Era.

HARVEY, D. [1973] (1978). Urbanismo y desigualdad social. Madri, Siglo XXI.

[1982] (1990). Los límites del capitalismo y la teoría marxista. México, Fondo de Cultura Económica.

[2000] (2003). Espacios de esperanza. Madri, Akal.

JARAMILLO GONZÁLEZ, S. (2009). Hacia una teoría de la renta del suelo urbano. Bogotá, Universidad de los Andes.

KALMANOVITZ, S. (1977). Ensayos sobre el desarrollo del capitalismo dependiente. Bogotá, Pluma.

(1982). Cuestiones de método en la teoría del desarrollo. Comercio Exterior, v. 32, n. 5. México, Bancomext.

MÁRQUEZ LÓPEZ, L. e COBOS, E. P. (2004). Estancamiento económico, desindustrialización y terciarización informal en la Ciudad de México, 1980-2003, y potencial de cambio. Investigación y Diseño, n. 1. México, Universidad Autónoma Metropolitana, Unidad Xochimilco.

(2007). Ciudad de México: el automóvil contra el transporte público. Investigación y Diseño, n. 4. México, Universidad Autónoma Metropolitana, Unidad Xochimilco.

(2008). Desindustrialización, terciarización y estructura metropolitana: un debate conceptual necesario. Cuadernos del CENDES, n. 69. Caracas, Universidad Central de Venezuela.

MARX, K. [1857-1858] (1972). Elementos fundamentales para la crítica de la economía política. Borrador, v. 2. Buenos Aires, Siglo XXI.

[1867] (1975). El Capital. México, Siglo XXI.

PEREIRA, P. C. X. (org.) (2011). Negócios inmobiliários e transformaciones sócio-territoriais em ciudades da América Latina. São Paulo, Universidade de São Paulo.

POLANYI, K. [1957] (2001). La gran transformación. Los orígenes políticos y económicos de nuestro tiempo. México, Siglo XXI.

PORTES, A. e ROBERTS, B. R. (2005). “La ciudad bajo el libre mercado”. In: PORTES, A.; ROBERTS, B. R. e GRIMSON, A. (eds.). Ciudades latinoamericanas. Un análisis comparativo en el umbral del nuevo siglo. Buenos Aires, Prometeo Libros. 
PRADILLA COBOS, E. (1981). Desarrollo capitalista dependiente y proceso de urbanización en América Latina. Revista Interamericana de Planificación, v. XV, n. 57. México, Sociedad Interamericana de Planificación.

(1984). Contribución a la crítica de la teoría urbana. Del espacio a la crisis urbana. México, Universidad Autónoma Metropolitana, Unidad Xochimilco.

(2009). Los territorios del neoliberalismo en América Latina. México, Universidad Autónoma Metropolitana, Unidad Xochimilco/Miguel Ángel Porrúa.

(2010a). Mundialización neoliberal, cambios urbanos y políticas estatales en América Latina. Cadernos Metrópole, n. 24. São Paulo, Educ.

(2010b). Teorías y políticas urbanas: ¿Libre mercado mundial o construcción regional? Revista Brasileira de Estudos Urbanos e Regionais, v. 12, n. 2. São Paulo.

(2011). "Zona Metropolitana del Valle de México: una ciudad baja, dispersa, porosa y de poca densidad". In: COBOS, E. P. (comp.). Ciudades compactas, dispersas, fragmentadas. México, Universidad Autónoma Metropolitana, Unidad Xochimilco/Miguel Ángel Porrúa.

(2012). Formas productivas, fracciones del capital y re-construcción urbana en América Latina. México, Universidad Autónoma Metropolitana.

PRADILLA COBOS, E. e HIDALGO, R. A. P. [2002] (2004). Ciudad de México: de la centralidad a la red de corredores urbanos. Anuario de Espacios Urbanos. México, Universidad Autónoma Metropolitana, Unidad Azcapotzalco/Gernika.

PRADILLA COBOS, E.; GALVÁN, F. M. e LÓPEZ, L. M. (2012a). "Cambios económicos y morfológicos en la Zona Metropolitana del Valle de México". In: DUHAU, E. (ed.). Ciudad de México: la construcción permanente de la metrópoli. Quito, Olacchi.

(2012b). “Changements économiques, sociaux et morfhologiques dans la zone métropolitaine de la Valée de Mexico (1980-2010)". In: TELLIER, L-N. e VAINER, C. (comps.). Métropoles des Ameriques en mutation. Quebec, Presses de I'Université de Quebec.

PRADILLA COBOS, E. (coord.), CARPYNTEIRO, C. C.; FlÓREZ, L. O. D.; DIEGO, C. H.; CHAPA, F. G. N.; GALVÁN, F. DE J. M.; HIDALGO, R. A. P.; SANTIAGO DE LA CRUZ, C. e RÍOS, C. V. Zona Metropolitana del Valle de México: cambios demográficos, económicos y morfológicos. México, Proyecto Conacyt-UAM parte I, inédito.

PRADILLA COBOS, E. (coord.), MEJÍA, H. B.; FLORES, L. O. D.; DIEGO, C. H.; ROBLES, F. F. M.; GALVÁN, F. DE J. M.; HIDALGO, R. A. P. e SANTIAGO DE LA CRUZ, C. Zona Metropolitana del Valle de México: cambios sociales. México, Proyecto Conacyt-UAM parte II, inédito.

PUEBLA, C. (2002). Del intervencionismo estatal a las estrategias facilitadoras. Cambios en la política de vivienda en México. México, El Colegio de México.

RAMíREZ VELÁZQUEZ, B. R. e COBOS, E. P. (comps.) (2013). Teorías sobre la ciudad en América Latina. México, Universidad Autónoma Metropolitana.

ROZO, C. A. (2010). Caos en el capitalismo financiero global. México, Océano/Universidad Autónoma Metropolitana, Unidad Xochimilco. 
RUBALCAVA, R. M. e SCHTEINGART, M. (2012). Ciudades divididas. Desigualdad y segregación social en México. México, El Colegio de México.

SABATINI, F. (2003). La segregación social del espacio en las ciudades de América Latina. Washington, Banco Interamericano de Desarrollo.

SALAMA, P. (2012a). Globalización comercial: desindustrialización prematura en América Latina e industrialización en Asia. Comercio Exterior, v. 62, n. 6. México, Bancomext.

(2012b). ¿Cambios en la distribución del ingreso en las economías de América Latina? Foro Internacional 209, LII.

SINGER, P. (1973). “Urbanización, dependencia y marginalidad en América Latina”. In: CASTELLS, M. (comp.). Imperialismo y urbanización en América Latina. Barcelona, Gustavo Gilli.

TAMAYO, S. (2010). Crítica de la ciudadanía. México, Universidad Autónoma Metropolitana, Unidad Azcapotzalco/Siglo XXI.

TOKMAN, V. R. (2007). Informalidad, inseguridad y cohesión social en América Latina. Santiago de Chile, Cepal.

VALENZUELA FEIJOO, J. (1991). Crítica del modelo neoliberal. México, Facultad de Economía, UNAM. WALLERSTEIN, I. [1983] (1988). El capitalismo histórico. México, Siglo XXI.

Texto recebido em 31/out/2013

Texto aprovado em 20/nov/2013 